\title{
HEPATITIS B AND C INFECTION: IS IT A PROBLEM IN POLISH HEALTHCARE WORKERS?
}

\author{
MARCIN RYBACKI ${ }^{1}$, ANNA PIEKARSKA ${ }^{2}$, MARTA WISZNIEWSKA ${ }^{1}$, \\ and JOLANTA WALUSIAK-SKORUPA ${ }^{1}$ \\ ${ }^{1}$ Nofer Institute of Occupational Medicine, Łódź, Poland \\ Department of Occupational Diseases and Toxicology \\ ${ }^{2}$ Medical University of Łódź, Łódź, Poland \\ Department of Infectious Diseases and Hepatology
}

\begin{abstract}
Objectives: Hepatitis B (HBV) and C viruses (HCV) are among the most frequent blood borne pathogens. According to WHO, $5 \%$ of healthcare workers (in central Europe), are exposed to at least one sharps injury contaminated with HBV per year, 1,7\% - contaminated with HCV. Aims: The aims of the study were to determine prevalence of HCV and HBV infections, vaccination efficacy against hepatitis B and usefulness of alanine aminotransferase (ALT) testing in prophylactic examinations in healthcare workers (HCWs). Material and Methods: In a group of 520 healthcare workers, a survey, laboratory and serologic tests such as ALT, HBsAg, anti-HBs, anti-HBcT and anti-HCV were carried out. Results: The study revealed a low rate of workers with presence of $\mathrm{HBsAg}$ and anti-HCV (1,2\% and 0,8\% respectively). Anti-HBcT was found in 99 subjects (19\%) without a significant association with experiencing an occupational percutaneous injury. Being vaccinated against HBV was declared by $90 \%$ of the subjects. There was no relationship between ALT level rise and positive HBsAg, anti-HCV and anti-HBcT tests. Conclusion: A seroprevalence of HBV and HCV markers in HCWs found in the study is low and similar to the one found in general population. Current or past hepatitis B infections were independent of needle stick injuries. Vaccination against HBV coverage, although found to be high, should improve to $100 \%$. Occupational prophylactic medical examinations found performing ALT test (obligatory in Poland for HCWs) not helpful. It seems that determination of anti-HBcT and anti-HCV status would be essential in pre-employment medical examinations.
\end{abstract}

Key words:

Healthcare workers, HBV prevalence, $\mathrm{HCV}$ prevalence, Hepatitis B vaccination, ALT testing

\section{INTRODUCTION}

It's known that hepatitis B (HBV) and C viruses (HCV) are among the most frequent blood borne pathogens. Occupational exposure to them refers mainly to healthcare workers because of frequent contact with body fluids [1,2]. The risk of transmitting an infection following an occupational exposure depends on lots of factors and is on average $0.5 \%$ for $\mathrm{HCV}$ and $18-30 \%$ for $\mathrm{HBV}$ [3-5]. In United States it's been estimated that a prevalence of HBV infection among healthcare workers (HCWs) was approximately 10 times higher than among the general population [5]. Although the risk of being infected with $\mathrm{HBV}$ is greater than $\mathrm{HCV}$, there are efficient means of pre- and post-exposure prophylaxis (hepatitis B immunoglobulin and/or hepatitis B vaccine - obligatory for HCWs).

According to the World Health Organization, 5\% of HCWs in central part of Europe are exposed to at

This study was supported by funds from European Social Fund, Human Capital Operational Program (National Strategic Reference Framework). Received: August 14, 2012. Accepted: November 26, 2012.

Corresponding author: M. Rybacki, Department of Occupational Diseases and Toxicology, Nofer Institute of Occupational Medicine, św. Teresy 8, 91-348 Łódź, Poland (e-mail: mrybacki@imp.lodz.pl). 
least one sharps injury contaminated with HBV per year and $1.7 \%$ - to the one contaminated with HCV [6].

Polish Chief Sanitary Inspectorate estimates there were about 1513 new cases of hepatitis B in 2009 in Poland and there are 450000 people infected with HBV. Implementing obligatory vaccinations against HBV in children and adolescents (1994) immunized individuals up to the age of 18 against this virus. In the vaccinated group acute hepatitis B is rarely observed [7,8]. Hepatitis C morbidity is dissimilar to the one caused by HBV; the extent of years is increasing, although in 2007-2009 this trend was revised. It's estimated that there are about 730000 people infected with $\mathrm{HCV}$ with a morbidity rate of 7-8 cases per 100000 inhabitants [7-10]. The most often genotypes recognized in Poland are: $1 \mathrm{~b}$ (75\%), 3a (17\%) and 1a (about 5\%) [11,12].

All employees in Poland are obliged to undergo pre-employment and periodic medical examinations. The only laboratory tests that are compulsory for workers being at risk of exposure to HBV and HCV (according to the Polish guidelines on prophylactic examinations) to acquire are total serum bilirubin and alanine aminotransferase (ALT). Serologic tests aimed at early detection of HBV and $\mathrm{HCV}$ infection are facultative. As an employer covers the costs of prophylactic care, performing these tests quite often depends on the amount of money the healthcare setting wants to spend on laboratory tests.

In Poland, there were in total 2933 occupational diseases diagnosed in 2010. Recently, there are around 30-45 occupational cases of hepatitis B and 99-119 of hepatitis C recognized per year, mostly in healthcare workers [13].

The aims of the study were to determine prevalence of HCV and HBV infections, their association with occupational exposure and not work-related risk factors, vaccination against hepatitis B efficacy and usefulness of ALT testing in prophylactic examinations in healthcare workers. The evaluation of awareness of being infected with HBV in the past was also made to determine how many workers were unnecessarily vaccinated.

\section{MATERIAL AND METHODS}

The study was conducted from January to December 2009. Ten healthcare settings in Łódź county (Poland) were selected using a table of random numbers from a list obtained from the Łódź Health Department; consent and permission to conduct a survey were also requested. Five of the selected that responded were included into the study. From a total number of 1878 healthcare employees, a group of 600 workers were randomly selected by using a table of random numbers, of which 520 agreed to take part in a study $(86.7 \%)$. All participants completed a questionnaire designed by authors partly based on questions presented in Survey of Healthcare Personnel on Occupational Exposure to Blood and Body Fluids developed by Centers for Disease Control and Prevention (CDC), and described in Sharps Injury Prevention Workbook [14]. Among 50 workers (which were included in the final study population) a pilot study was conducted. Comments obtained from this group contributed reasons for some revision of the questions.

\section{Questionnaire}

The questionnaire included questions on: job category (nurses, surgical medical staff, ward attendants, non-surgical medical staff, dental personnel (dentists and dental assistants), laboratory staff), place of work (hospital, outpatient clinic), job seniority, vaccination against HBV status, history of exposure to percutaneous injuries, number of occupational exposures and non-work related history that posed a risk of transmission of blood borne viruses (like surgeries, dialysis, piercing or endoscopic tests).

\section{Laboratory tests}

In all subjects, $4 \mathrm{ml}$ of blood was collected for laboratory and serologic tests such as alanine aminotransferase (ALT), hepatitis B virus surface antigen (HBsAg), hepatitis $B$ virus surface antigen antibodies (anti-HBs), total hepatitis $\mathrm{B}$ virus core antigen antibodies (anti-HBcT) and hepatitis $\mathrm{C}$ antibodies (anti-HCV). 
Detecting anti-HCV, $\mathrm{HBsAg}$, anti-HBs and anti-HBcT was performed by enzyme immunoassays (ECLIA, Roche) according to the manufacturer's instruction. Anti-HBs concentration equal to or greater than $10 \mathrm{IU} / 1$ was considered positive. ALT was tested using COBAS Integra tests. Laboratory testing was made in a referential laboratory of the Infectious Diseases Hospital in Łódź. Anti-HBcT positive individuals were analyzed in regard to job seniority (divided into 4 groups: working no longer than 10 years, between 11-20 years, 21-30 years and longer than 30 years), history of hepatitis B (awareness of being infected with HBV in the past), vaccination against HBV, occupational exposure and other non-work related risk of infection. Due to a low number of $\mathrm{HBsAg}$ and anti-HCV positive workers, no such analyses were done for these markers.

The Regional Bioethical Committee approved the study protocol. All of the participants gave informed consent prior to the study.

\section{Statistical analysis}

Sample size was estimated on the basis of a following assumption: occupational exposure rate at $40 \%$, percentage of anti-HBcT positive workers $-20 \%$, twofold risk of anti-HBcT positivity in exposed workers $(\mathrm{OR}=2)$, the power of inference not lower than $95 \%, \alpha$ ratio $=0.05$.

Continuous variables were expressed as mean values \pm standard deviations (SD) while the nominal variables as numbers and percentages. Associations between dependent variable and group of independent variables (clinical and laboratory parameters) were assessed in logistic regression analysis. The odds ratios describing the strength of association between discrete variable and nominal or categorized independent variables were estimated in univariate model. For categorized variables the first categories were defined as reference. All statistical analyses were performed using STATISTICA 8.0; $p<0.05$ was used as a definition of statistical significance.

\section{RESULTS}

The study group comprised: 260 (50\%) nurses, 50 (9.6\%) surgical medical staff, $45(8.6 \%)$ ward attendants, $54(10.4 \%)$ nonsurgical medical staff, 57 (11\%) dental personnel, 25 (4.8\%) laboratory staff and $29(5.6 \%)$ other HCWs. This group consisted of 377 (72.5\%) hospital-based workers, 98 (18.8\%) outpatient clinic workers and 45 (8.7\%) workers employed in other healthcare settings. The mean age of the subjects was $44.42 \pm 8.66$ years ( $\min .22$, max. 75 ) while the mean job seniority in healthcare was $21.02 \pm 9.42$ years (min. 2 months; max. 45 years). 467 (89.8\%) of them declared being vaccinated against HBV, 46 (8.9\%) have never undergone vaccination and $7(1.3 \%)$ couldn't recall a fact of vaccination. The results of performed laboratory tests are shown in Table 1.

Table 1. Results of laboratory tests performed in a group of $520 \mathrm{HCWs}$

\begin{tabular}{lc}
\hline \multicolumn{1}{c}{ Laboratory test } & $\begin{array}{c}\text { Respondents }(\mathrm{N}=520) \\
\mathrm{n}(\%)\end{array}$ \\
\hline $\begin{array}{l}\text { ALT above normal range }(>40 \mathrm{IU} / \mathrm{l}) \\
\text { HBs antigen }\end{array}$ & $28(5.4)$ \\
positive & $6(1.2)$ \\
negative & $513(98.6)$ \\
undefined & $1(0.2)$ \\
Anti-HBs level (IU/l) & \\
$<10$ & $69(13.3)$ \\
$10-100$ & $87(16.7)$ \\
$>100$ & $364(70.0)$ \\
Anti-HBc total & \\
positive & $99(19.0)$ \\
negative & $416(80.0)$ \\
undefined & $5(1.0)$ \\
Anti-HCV antibodies & \\
positive & $4(0.8)$ \\
negative & $511(98.2)$ \\
undefined & $5(1.1)$ \\
\hline
\end{tabular}

HCW - healthcare worker; ALT - alanine aminotransferase; HBs surface antigen of hepatitis B virus; HCV - antibodies to hepatitis $\mathrm{C}$ virus; Anti-HBc - antibodies to core antigen of hepatitis B virus; Anti-HBs - antibodies to surface antigen of hepatitis B virus. 
Among 520 of HCWs, HBsAg was detected in 6 subjects $(1.2 \%)$, and 4 of them were aware of being HBsAg carrier. Anti-HCV positive results were found in 4 workers $(0.8 \%)$ and only 1 person knew of being infected with HCV. Prevalence of positive HBsAg, anti-HBcT and anti-HCV in different categories of independent variables is shown in Table 2.
ALT levels in subjects positive for HBsAg, anti-HBcT and anti-HCV were analyzed. There was no case of an ALT rise in $\mathrm{HBsAg}$ positive or anti-HCV positive workers. Slightly elevated ALT levels (from 42 to 61) were found only in 9 anti-HBcT positive subjects (9\%). From all 28 cases presenting elevated ALT levels (above $40 \mathrm{IU} / \mathrm{l}$ ), in 19 subjects $(67.9 \%)$, viral hepatitis as a cause of raised liver

Table 2. Prevalence of positive HBsAg, anti-HBcT and anti-HCV results according to job seniority, history of viral hepatitis B and C, vaccination status, occupational percutaneous injury, not-work related risk of infection and ALT level above 40 IU/l in a group of $520 \mathrm{HCWs}$

\begin{tabular}{|c|c|c|c|c|}
\hline \multirow[t]{2}{*}{ Independent variables } & \multirow{2}{*}{$\begin{array}{c}\text { Respondents } \\
(\mathrm{N}=520) \\
(\mathrm{n})\end{array}$} & \multicolumn{3}{|c|}{$\begin{array}{l}\text { Positive serologic tests } \\
\mathrm{n}(\%)\end{array}$} \\
\hline & & HBsAg & anti-HBcT & anti-HCV \\
\hline \multicolumn{5}{|l|}{ Job seniority (years) } \\
\hline$\leq 10$ & 94 & $0(0)$ & $6(6.4)$ & $0(0)$ \\
\hline $11-20$ & 166 & $2(1.2)$ & $22(13.2)$ & $0(0)$ \\
\hline $21-30$ & 182 & $3(1.6)$ & $44(24.2)$ & $4(2.2)$ \\
\hline$>30$ & 78 & $1(1.3)$ & $27(34.6)$ & $0(0)$ \\
\hline \multicolumn{5}{|l|}{ History of viral hepatitis type B } \\
\hline yes & 43 & $4(9.3)$ & $29(67.4)$ & $0(0)$ \\
\hline no & 477 & $2(0.4)$ & $70(1.5)$ & $4(0.8)$ \\
\hline \multicolumn{5}{|l|}{ History of viral hepatitis type $C$} \\
\hline yes & 3 & $1(33.3)$ & $1(33.3)$ & $1(33.3)$ \\
\hline no & 517 & $5(1.0)$ & $98(18.9)$ & $3(0.6)$ \\
\hline \multicolumn{5}{|l|}{ Vaccination against $\mathrm{HBV}$} \\
\hline yes & 467 & $1(0.2)$ & $78(16.7)$ & $3(0.6)$ \\
\hline no & 46 & $5(10.9)$ & $21(45.6)$ & $1(2.2)$ \\
\hline Unknown & 7 & $0(0)$ & $0(0)$ & $0(0)$ \\
\hline \multicolumn{5}{|l|}{ Occupational percutaneous injury } \\
\hline yes & 197 & $3(1.5)$ & $45(22.8)$ & $2(1.0)$ \\
\hline no & 323 & $3(0.9)$ & $54(16.3)$ & $3(1.0)$ \\
\hline \multicolumn{5}{|l|}{ Not-work related risk of infection } \\
\hline yes & 287 & $1(0.3)$ & $54(18.8)$ & $3(1.0)$ \\
\hline no & 233 & $5(2.1)$ & $45(19.3)$ & $1(0.4)$ \\
\hline \multicolumn{5}{|l|}{ ALT above $40 \mathrm{IU} / \mathrm{l}$} \\
\hline yes & 28 & $0(0)$ & $9(32.1)$ & $0(0)$ \\
\hline no & 492 & $6(1.2)$ & $90(18.3)$ & $4(0.8)$ \\
\hline
\end{tabular}

HBV - hepatitis B virus. Other abbreviations as in Table 1. 
Table 3. Association between elevated ALT (> $40 \mathrm{IU} / \mathrm{l}$ ) (dependent variable) and job seniority, history of viral hepatitis B and C, vaccination status, occupational percutaneous injury, not-work related risk of infection, presence of anti-HBcT and anti-HBs $>10 \mathrm{IU} / \mathrm{l}$ (independent variables) in a group of $520 \mathrm{HCWs}$ in the univariate model of logistic regression analysis

\begin{tabular}{lcccc}
\hline \multicolumn{1}{c}{ Independent variables } & OR & $-95 \%$ CI & $+95 \%$ CI & $\mathrm{p}$ \\
\hline Job seniority (years) & ref & & & \\
$\leq 10$ & 0.90 & 0.29 & 2.84 & 0.80 \\
$11-20$ & 1.15 & 0.39 & 3.40 & 0.80 \\
$21-30$ & 0.96 & 0.25 & 3.71 & 0.90 \\
$>30$ & 1.36 & 0.39 & 4.69 & 0.60 \\
History of viral hepatitis type B & - & - & - & - \\
History of viral hepatitis type C* & 1.22 & 0.47 & 3.19 & 0.60 \\
Vaccination & 1.45 & 0.68 & 3.12 & 0.30 \\
Occupational percutaneous injury & 1.50 & 0.68 & 3.33 & 0.30 \\
Not-work related risk of infection & - & - & - & - \\
Presence of HBs antigen* & 0.91 & 0.31 & 2.72 & 0.80 \\
Presence of anti-HBs $>$ 10 IU/l & 2.09 & 0.92 & 4.77 & 0.08 \\
Presence of anti-HBcT & & & & \\
\hline
\end{tabular}

OR - odds ratio; $\mathrm{CI}$ - confidence interval. Other abbreviations as in as Table 1 and 2.

* OR could not be estimated.

enzyme could have been ruled out. Relationships between elevated ALT levels (as dependent variable) and a range of clinical and laboratory parameters were also assessed (see Table 3). There were no statistical predictors of elevated ALT levels that confirms the lack of association between ALT levels and the presence of HBs antigen or the presence of anti-HBcT.

The presence of anti-HBcT was significantly more frequent in subjects working between 21-30 years and longer than 30 years $(\mathrm{OR}=4.75, \mathrm{p}=0.006$ and $\mathrm{OR}=8.08$, $\mathrm{p}<0.0001$ respectively).

Out of 99 anti-HBcT positive workers, 78 (78.8\%) declared being vaccinated against $\mathrm{HBV}$ and only 29 (29.3\%) confirmed being infected with the hepatitis B virus. Among those anti-HBcT positive HCWs, there were fewer vaccinated subjects in a group with history of hepatitis $B$ than in a group that denied having a HBV infection (13/29 vs. 65/70). In the univariate model of logistic regression analysis, being vaccinated significantly lowers the probability of anti-HBcT positivity $(\mathrm{OR}=0.23$, $\mathrm{p}<0.0001)$.

There were bigger percentages of anti-HBcT positive workers in a group that admitted experiencing at least one occupational percutaneous injury than in a group without such history (45/197 vs. 54/323), but these differences were not statistically significant $(\mathrm{OR}=1.48, \mathrm{p}=0.08)$. Presence of non-occupational risk factors for HBV infection didn't affect anti-HBcT presence either $(\mathrm{p}=0.894)$. Detailed results are shown in Table 4.

Positive anti-HBs concentration was found in 451 individuals $(86.7 \%)$. Among these workers, 20 admitted to never being vaccinated against $\mathrm{HBV}$. In these 20 subjects -15 were anti-HBcT positive, in one case anti-HBcT was unsettled and 4 were anti-HBcT negative. 7 workers with protective concentration of anti-HBs could not remember whether they were vaccinated. Anti-HBs concentration lower than $10 \mathrm{IU} / \mathrm{l}$ was found in 69 subjects and 26 of them admitted to never being vaccinated against HBV. 
Table 4. Association between presence of anti-HBcT (dependent variable) and history of viral hepatitis B, vaccination status, occupational percutaneous injury and non-work related risk of infection (independent variables) in a group of $520 \mathrm{HCWs}$ in the univariate model of logistic regression analysis

\begin{tabular}{|c|c|c|c|c|}
\hline Independent variables & OR & $-95 \% \mathrm{CI}$ & $+95 \% \mathrm{CI}$ & $\mathrm{p}$ \\
\hline \multicolumn{5}{|l|}{ Job seniority (years) } \\
\hline$\leq 10$ & ref & & & \\
\hline $11-20$ & 2.26 & 0.88 & 5.78 & 0.09 \\
\hline $21-30$ & 4.75 & 1.94 & 11.60 & 0.0006 \\
\hline$>30$ & 8.08 & 3.12 & 20.92 & $<0.0001$ \\
\hline History of viral hepatitis type B & 11.90 & 5.99 & 23.63 & $<0.0001$ \\
\hline Vaccination & 0.23 & 0.12 & 0.44 & $<0.0001$ \\
\hline Occupational percutaneous injury & 1.48 & 0.95 & 2.30 & 0.08 \\
\hline Not-work related risk of infection & 0.97 & 0.62 & 1.51 & 0.8 \\
\hline
\end{tabular}

Abbreviations as in Table 1-3.

Non-protective anti-HBs level was found in 43 vaccinated workers, which made up $9.2 \%$ of all vaccinated subjects. Three subjects were found to be anti-HBcT positive with anti-HBs and HBsAg negative status. There was also one HBsAg positive worker with anti-HBs titer greater than $10 \mathrm{IU} / \mathrm{l}$ (anti-HBs = $22 \mathrm{IU} / \mathrm{l})$.

\section{DISCUSSION}

The study revealed a low rate of workers positive for HBsAg and anti-HCV (1.2\% and $0.8 \%$ respectively). It is comparable with the rate found in general population in Poland. Since introducing obligatory vaccinations against hepatitis $\mathrm{B}, \mathrm{HBV}$ morbidity rate has systematically decreased. Nowadays there are about 4-5 cases per 100.000 inhabitants and is similar to other European countries. HBsAg carrier status is around 1\% [9]. Low rate of positive for HBsAg and anti-HCV HCWs was also found in different studies. In Italy, HBsAg and anti-HCV positivity was found in $0.4 \%$ and $0.8 \%$ HCWs respectively [15]. A study conducted in Turkey, where anti-HCV seroprevalence in HCWs was compared with one found in blood-donors as a control group revealed that among 702 employees, anti-HCV antibodies were found only in $0.3 \%$ of the employees and this rate was even lower than in the control group $(0.4 \%)$. This fact was explained by a generally low prevalence of hepatitis $\mathrm{C}$ in Turkey, a strict compliance with universal precautions, a low number of drug-addicts, tattooing and risky sexual behavior [16]. In Israel, antiHCV was found in $0.9 \%$ of 4287 hospital employees and no association between the presence of anti-HCV and a history of percutaneous injury was observed [17]. In Poland, a study conducted in $4248 \mathrm{HCWs}$ in the northern region (Pomerania) showed the prevalence of anti-HCV antibodies was $1.3 \%$ [18].

The seroprevalence of anti-HBcT in our study was found to be $19 \%$, but it's difficult to estimate whether it's higher than in a general population. These antibodies are found in $7 \%$ of Polish blood donors, although it is estimated that there are more people with history of HBV infection in a general population. Some other data suggest that hepatitis B core antigen antibodies are found in $20 \%$ of inhabitants [19,20]. Another Polish study conducted in surgical nurses and midwives revealed the prevalence rate for HBsAg to be $0.7 \%$ and $16.4 \%$ for anti-HBcT [21]. Anti-HBcT may be positive during the chronic carrier stage, and at the end of an acute resolving infection where HBsAg may be undetectable. The presence of anti-HBcT was more frequent in employees 
working between 21-30 years and longer than 30 years in comparison to those working shorter $(\mathrm{OR}=4.75$ and 8.08 vs. 2.26). These differences could be explained by the introduction of obligatory vaccination against HBV in 1994, that efficiently lowered the number of new infections. Subjects with a longer job-seniority could have acquired hepatitis B before getting vaccination.

There was no ALT level rise in positive HBsAg or anti$\mathrm{HCV}$ workers, although from clinical point of view these situations are common and depend on natural history of viral hepatitis. Some use raised ALT levels as a marker of recent viral hepatitis infection, but levels of this enzyme are not specific to this contagion and may fluctuate; moreover, even people with normal serum ALT levels present histologic evidence of hepatitis $\mathrm{C}$ chronic inflammation in the majority of cases [22,23]. In regard to occupational prophylactic medical examinations, testing exclusively for ALT levels (obligatory in Poland for HCWs) is not useful, as an infection with HBV or HCV could be easily missed. Determination of anti-HBcT status would be essential in initial examinations. Performing a serologic test could be helpful in detection of hepatitis B (a current or past infection) and in ruling out the current healthcare setting as a place where occupational disease might have been acquired. Establishing the necessity of worker's vaccination (if not vaccinated) would also be a benefit from this serologic test (although pre-vaccination screening is not routinely recommended [24]). The study revealed that $78.8 \%$ of anti-HBcT positive individuals were unnecessarily vaccinated, this made up $16.7 \%$ of all vaccinated workers (78 out of 467). In regard to risk of being exposed to HCV, anti-HCV antibodies should be the basic laboratory test performed at the employee's pre-employment examinations. Further testing should be carried out after needle sticks involving HCV-positive blood or in case when signs or symptoms of liver malfunction occur.

Three cases of anti-HBcT positive alone (HBsAg and antiHBs negative) should have undergone further diagnostics, although it wasn't a part of a study. It's common that the diagnosis of $\mathrm{HBV}$ infection is based on the presence of HBsAg, although the absence of this marker doesn't exclude the possibility of HBV-DNA presence (serologic profile called occult HBV infection). There are a few possibilities explaining the anti-HBcT alone status. It can be a falsepositive result, a late acute resolving infection with undetectable HBsAg but with persistence of low level of HBV DNA for a short time, a chronic carrier state with HBsAg levels below the detection limit of current assays or HBV infection with a virus carrying mutations resulting in undetectable HBsAg [25]. Some studies show that prevalence of HBV-DNA is higher in anti-HBcT alone positive cases than in both anti-HBcT and anti-HBs positive samples [26]. It's been estimated that HBV-DNA is detectable in 0.3$15 \%$ of anti-HBcT alone blood donors [27]. It's been proven that prevalence of DNA-positive results in anti-HBcTalone patients is increased in areas with a higher prevalence of HBV infection. Even if these subjects are false positive, complementary tests should be performed to confirm antiHBcT reactivity [24,28,29].

Our study revealed good vaccination against HBV coverage in HCWs (89.8\%). Almost half of 46 subjects who have never undergone vaccination were found to be anti-HBcT positive, which made them naturally protected and thus there was no need of vaccination. Still, the others should be investigated for reasons of not being vaccinated. The study revealed an anti-HBs level lower than $10 \mathrm{IU} / \mathrm{l}$ in $9.2 \%$ of all vaccinated subjects. Unfortunately we can't assume whether these individuals didn't primarily respond to the vaccination or lost their anti-HBs-producing capacity after a long period of last vaccination dose. Nowadays it's believed that despite lack of these antibodies, people are protected against infection or reinfection by cellular immune mechanisms and immunological memory. This is why booster doses of vaccine and periodic antibody concentration testing are not routinely recommended in case of a drop of antibody level $[5,28,30,31]$. The assessment of response after 
completion of vaccine series is not common in Poland, not only in general population, but in HCWs as well. The study shows the importance of introducing mandatory testing for anti-HBs level in 1-2 months after completing vaccination to make sure that $100 \%$ of employees are aware of their vaccination response and protection against $\mathrm{HBV}$ infection. This will also be helpful in managing HBV post exposure prophylaxis in employees with low titer of anti-HBs presented at the time of exposure. According to the European recommendations in previously vaccinated and known responders there is no need to take up any actions [24].

Surprisingly 4 anti-HBcT negative subjects who declared not being vaccinated, had protective titer of anti-HBs. Possible explanation for the presence of anti-HBs antibodies is that these individuals did not remember being vaccinated or the anti-HBcT results were false negative.

The study has some limitations, like not having a full participation rate. Lack of time or not being interested in HBV and HCV status could be an explanation. Infected HCWs could have avoided taking part in the study on purpose. Sometimes subjects do not approve of testing for $\mathrm{HBV}$ and $\mathrm{HCV}$ in case they are positive for these viruses; they fear of losing their jobs, although in Poland contrary to other countries - there aren't any regulations that an infected personnel is not allowed to perform exposure-prone procedures. This could also explain a low rate of HCV and HBV infections found in our study.

Prevalence data indicate that the rate of HCV and HBV infections in HCWs is low. It can be explained by low prevalence of $\mathrm{HBV}$ and $\mathrm{HCV}$ in general population in our country, compliance with universal precautions and good vaccination against HBV coverage. Positive results for anti-HBcT found in our study had no association with a history of occupational percutaneous injury, so employment in healthcare cannot be regarded as a major risk of contracting hepatitis $\mathrm{B}$ infection. However, HCWs are at risk of exposure to hepatitis $\mathrm{B}$ and $\mathrm{C}$ viruses and thus all means must be involved in creating a safer workplace.
Good hepatitis B vaccination coverage, reaching nearly $90 \%$, and a similar percentage of HCWs with a protective level of anti-HBs antibodies was revealed. When defining vaccination necessity, anti-HBcT results should be taken into consideration. There was no need to vaccinate in almost $20 \%$ of HCWs, this contributes to wasting of funds. It also seems that changing the official guidelines on obligatory laboratory tests performed in healthcare employees is necessary, as only carrying out ALT and bilirubin tests (without serologic testing) is not helpful in the detection of hepatitis $\mathrm{B}$ and $\mathrm{C}$ infection.

\section{REFERENCES}

1. Centers for Disease Control and Prevention (US). Service guidelines for the management of occupational exposures to HBV, HCV and HIV - Present CDC guidelines. Med Prakt 2002;11:147-63 [in Polish].

2. Ferreiro MC, Dios PD, Scully C. Transmission of hepatitis $C$ virus by saliva? Oral Dis 2005;11:230-5.

3. Yazdanpanah Y, De Carli G, Migueres B, Lot F, Campins M, Colombo C, et al. Risk factors for hepatitis C virus transmission to health care workers after occupational exposure: A European case-control study. Clin Infect Dis 2005;41:1423-30.

4. Werner BG, Grady GF. Accidental hepatitis-B-surface-antigenpositive inoculations. Use of $e$ antigen to estimate infectivity. Ann Intern Med 1982;97:367-9.

5. Beltrami EM, Alvarado-Ramy F, Critchley SE, Panlilio AL, Cardo DM, Bower WA, et al. Updated U.S. Public Health Service guidelines for the management of occupational exposures to $\mathrm{HBV}, \mathrm{HCV}$, and HIV and recommendations for postexposure prophylaxis. MMWR 2001;50(RR11):1-42.

6. Prüss-Üstün A, Rapiti E, Hutin Y. Sharps injuries: global burden of disease from sharps injuries to health-care workers [cited 2011 Dec 2]. Geneva: World Health Organization (WHO Environmental Burden of Disease Series, No. 3); 2003. Available from URL: http://www.who.int/quantifying_ehimpacts/publications/en/sharps.pdf. 
7. Sanitary Chief Inspectorate. National Sanitary Condition in Poland in 2009 [cited 2010 Nov 5]. Warszawa: Sanitary Chief Inspectorate; 2010 [in Polish]. Available from URL: http://www.gis.gov.pl/userfiles/file/Stan\%20sanitarny\%20 kraju\%20w\%202009\%20roku.pdf.

8. Cianciara J, Grabowski ML. Epidemiologic condition of HBV and HCV infections in Poland. Med Dypl 2006;15(2):18-22 [in Polish].

9. Wojtyniak B, Gorynski P. The health situation of the Polish population. Warszawa: Narodowy Instytut Zdrowia Publicznego - Państwowy Zakład Higieny; 2008 [in Polish].

10. Gladysz A, Rymer W, Inglot M, Smolinski P. Viral hepatitis as a nosocomial infection - present and future legal regulations. Zakazenia 2004;1:44-51 [in Polish].

11. Cianciara J. Hepatitis B. In: Cianciara J, Juszczyk J, editors. Parasitic and infectious diseases. 1st ed. Lublin: Wydawnictwo Czelej; 2007. p. 593-6 [in Polish].

12. Juszczyk J. Viral hepatitis. In: Dziubek Z, editor. Parasitic and infectious diseases. 4th ed. Warszawa: Wydawnictwo Lekarskie PZWL; 2010. p. 313-42 [in Polish].

13. Szeszenia-Dabrowska N, editor. Occupational diseases in Poland in the year 2010. Łódź: Nofer Institute of Occupational Medicine; 2011 [in Polish].

14. Centers for Disease Control and Prevention(US). Sharps Injury Prevention Workbook [cited 2008 Oct 16] ALTanta: CDC. Appendix A-2, A-3. Available from URL: http://www.cdc. gov/sharpsafety/resources.html.

15. Baldo V, Floreani A, Dal Vecchio L, Cristofoletti M, Carletti M, Majori S, et al. Occupational risk of blood-borne viruses in healthcare workers: a 5-year surveillance program. Infect Control Hosp Epidemiol 2002;23:325-7.

16. Ozsoy MF, Oncul O, Cavuslu S, Erdemoglu A., Emekdas G, Pahsa A. Seroprevalances of hepatitis $B$ and $C$ among health care workers in Turkey. J Viral Hepat 2003;10:150-6.

17. Sermoneta-Gertel S, Donchin M, Adler R, Baras M, Perlstein T, Manny N, et al. Hepatitis $C$ virus infection in employees of a large university hospital in Israel. Infect Control Hosp Epidemiol 2001;22:754-61.
18. Zagozdzon P, Parszuto J, Raj A, Calus-Kania D, Korczak A, Ejsmont J. Prevalence and risk factors of chronic hepatitis $C$ virus infection among health-care workers in Pomeranian voivodeship. Przegl Epidemiol 2009;63(1):39-43 [in Polish].

19. Bilski B. Viral hepatitis as an occupational disease in Poland. Hepat Mon 2011;11(7):539-43.

20. Brojer E. Occult B infection in haematology and blood transfusion. Acta Haematol Pol 2009;40(2):435-49 [in Polish].

21. Ganczak M, Ostrowski M, Korzen M. A complete HBV vaccination coverage among Polish surgical nurses in the light of anti-HBc prevalence: A cross-sectional sero-prevalence study. Vaccine 2010;28:3972-6.

22. Lauer GM, Walker BD. Hepatitis C virus infection. N Engl J Med 2001;345:41-52.

23. Cornberg M, Manns MP, Wedemeyer H. Standard of care. In: Mauss S, Berg T, Rockstroth J, Sarrazin C, Wedemeyer H, editors. Hepatology 2009 - A clinical textbook [cited 2011 Oct 5]. Duesseldorf: Flying Publisher; 2009. p. 183-210. Available from: URL: http://www.HepatologyTextbook.com.

24. Puro V, de Carli G, Cicalini S, Soldani F, Balslev U, Begovac J, et al. European recommendations for the management of healthcare workers occupationally exposed to hepatitis $B$ virus and hepatitis $C$ virus [cited 2011 Oct 5]. Euro Surveill 2005;10(10):573. Available from: URL: http://www.eurosurveillance.org/ViewArticle. aspx?ArticleId=573.

25. Niederhauser C. Reducing the risk of hepatitis B virus transfusion-transmitted infection. J Blood Med 2011;2:91-102.

26. Asim M, Ali R, Khan LA, Husain SA, Singla R, Kar P. Significance of anti-HBc screening of blood donors and its association with occult hepatitis $B$ virus infection: Implications for blood transfusion. Indian J Med Res 2010;132:312-7.

27. Allain J. Occult hepatitis B virus infection. Hep B Annu 2005;2:14-30.

28. Ponde RAA, Cardoso DDP, Ferro MO. The underlying mechanisms for the "anti-HBc alone" serological profile. Arch Virol 2010;155:149-58. 
29. Silva AE, McMahon BJ, Parkinson AJ, Sjogren MH, Hoofnagle JH, Di Bisceglie AM. Hepatitis B Virus DNA in persons with isolated antibody to hepatitis $B$ core antigen who subsequently received hepatitis B vaccine. Clin Infect Dis 1998;26:895-7.

30. Van der Sande MAB, Waight PA, Mendy M, Zaman S, Kaye S, Sam O, et al. Long-term protection against $H B V$ chronic carriage of gambian adolescents vaccinated in infancy and immune response in $\mathrm{HBV}$ booster trial in adolescence [cited 2011 Aug 5]. PLOS ONE 2007;2(8):e753. DOI 10.1371/ journal.pone. 0000753 .

31. Centers for Disease Control and Prevention (US). A comprehensive immunization strategy to eliminate transmission of Hepatitis B Virus infection in the United States. MMWR 2006;55(RR-16):2-26.

This work is available in Open Access model and licensed under a Creative Commons Attribution-NonCommercial 3.0 Poland License - http://creativecommons.org/ licenses/by-nc/3.0/pl/deed.en. 